\title{
Dinâmicas de poder e insubordinação em “Danças húngaras de Brahms", de Teresa Veiga
}

\author{
Maria Araújo da Silva \\ Sorbonne Université - CRIMIC
}

Resumo: Em "Danças húngaras de Brahms", segundo dos três contos reunidos na colectânea As Enganadas (2003) de Teresa Veiga, cuja trama assenta basicamente nas relações entre uma mãe viúva e o seu filho de dezanove anos, defrontamo-nos, por um lado, com um discurso que celebra os pilares do patriarcado e reduz os indivíduos a "corpos dóceis" (Foucault 1975) moldados por práticas regulatórias e discursos padronizados e, por outro, com a representação de corporalidades e performatividades que visam questionar as dicotomias de género e as categorizações rígidas de identidade, género e sexualidade. Nele se revelam identidades que remetem para a subversão, a diferença, a marginalidade, que procuram desfazer condutas e discursos normativos e desafiar determinismos que condicionam as relações entre os indivíduos. Pretende-se assim demonstrar que o conto se constrói em torno de representações opressoras de sexo, género e identidade e da tentativa de derrubar dispositivos instituídos para servir o patriarcado diferencialista e hierarquizado, abrindo espaços para a transgressão e a resistência aos vários sistemas de poder, numa perspectiva amplamente libertadora.

Palavras-chave: Teresa Veiga; género; corpo; sexualidade; queer
Abstract: In "Danças húngaras de Brahms", second of the three short stories collected in Teresa Veiga's book As Enganadas (2003), whose plot is basically based on the relations between a widowed mother and her nineteen-year-old son, we are confronted, on the one hand, with a discourse that celebrates the pillars of patriarchy and reduces individuals to "docile bodies" (Foucault 1975) molded by regulatory and standardized 
practices and, on the other, with the representation of corporealities and performativities that intend to question gender dichotomies and rigid categorizations of identity and sexuality. The narrative presents identities that refer to subversion, difference, marginality, which seek to undo normative stances and discourses and challenge determinisms that condition the relations between individuals. The aim is to demonstrate that the tale is built around oppressive representations of sex, gender and identity and the attempt to overturn devices instituted to serve the differential and hierarchical patriarchy, opening spaces for transgression and resistance to various systems of power, in a markedly emancipatory and liberating perspective.

Keywords: Teresa Veiga; gender; body; sexuality; queer

Não são as nossas diferenças que nos dividem, mas a nossa incapacidade em reconhecer, aceitar e celebrar essas mesmas diferenças.

Audre Lorde

A arte, mesmo em segunda mão, é a grande consoladora dos males deste mundo.

Teresa Veiga

Em "Danças húngaras de Brahms", segundo dos três contos reunidos na colectânea As Enganadas (2003) de Teresa Veiga (Lisboa, 1945-), desenvolvem-se dinâmicas de poder e insubordinação, que procuraremos analisar na perspectiva dos estudos queer, centrandonos em personagens que se erguem contra diferentes práticas de dominação e opressão, multiplicando actos que contrariam modelos de comportamento socialmente instituídos, inibidores de uma afirmação singular e individual. Neste conto que nos incita a uma reflexão em torno das representações opressoras de sexo, género e identidade e das posturas que as refutam, deparamos, por um lado, com um discurso que celebra os pilares do patriarcado e reduz os indivíduos a "corpos dóceis" (Foucault 1975: 137) moldados por 
práticas regulatórias que os reprimem e, por outro, com a emergência de figuras que participam na desconstrução das dicotomias de género e das categorizações rígidas de identidade e sexualidade veiculadas pela moral burguesa dominante e socialmente reproduzidas. Remetendo para a subversão, a diferença, a margem, estas mesmas identidades desafiam normas regulatórias e discursos padronizados, abrindo espaços para a insubordinação e a resistência aos vários sistemas de poder, numa perspectiva marcadamente emancipatória e libertadora.

Antes de nos debruçarmos sobre o conto em análise, evoquemos por breves instantes o percurso de Teresa Veiga, pseudónimo de uma "autora-mistério" cuja actividade literária, iniciada em 1980, tem sido recebida com entusiasmo pela crítica que a inclui entre as grandes contistas portuguesas da actualidade. Avessa a qualquer protagonismo mediático, Teresa Veiga mantém ainda hoje em segredo os contornos da sua vida, sendo que os leitores apenas sabem que se licenciou em Direito em 1968 e em Filologia Românica em 1980 e exerceu, por um breve período de tempo, o cargo de Conservadora do Registo Civil nos arredores da capital. Da sua obra, constam sete livros dados à estampa, entre romances, novelas e contos, alguns representados em antologias nacionais e estrangeiras e galardoados com vários prémios literários. ${ }^{1}$

Tecendo com profundidade e talento um conjunto de emoções e de dramas humanos, o conto "Danças húngaras de Brahms" descreve a trajectória de uma mãe viúva, Faustina, minada pela ideia de que o seu único filho de dezanove anos, Fábio, possa ser homossexual. Dividida entre o medo de descobrir a verdadeira orientação sexual do filho e a tentação do desvendamento para pôr fim à angustia que a assola, Faustina decide finalmente "dar o primeiro passo na via do caminho sacrificial que decidira percorrer ao fim de uma longa luta travada com o seu Eu mais fraco" (Veiga 2003: 43), pelo que coloca esta sua Grande Preocupação (escrita, não por acaso, com maíusculas) entre as mãos de um detective encartado, de nome Lamartine, especializado em investigações em torno de comportamentos desviantes e transgressivos numa sociedade fortemente marcada por práticas de normalização e opressão institucionalizadas que o próprio encarna. Relativamente a esta personagem - verdadeiro "falcão no submundo da cidade" (idem: 50) 
- que não hesita em condenar, por vezes com uma agressividade arrogante, derivas e perversões susceptíveis de manchar a geografia social, o narrador heterodiegético deixa pairar, num tom irónico, uma certa ambiguidade sobre a relação que mantém com Tomé (ou Tom), um jovem de dezassete anos recrutado como estagiário "para todo o serviço" (idem: 50) no escritório que dirige:

Felizmente Tom não era simpático nem meigo nem bonito, o que tornava mais fáceis as coisas, pois assim podia andar com ele para todo o sítio e até oferecer-lhe ocasionalmente guarida na sua casita de fim de semana sem o risco de o tomarem por pervertido. (idem: 52)

Cultivando a arte da suspensão e envolvendo o leitor num verdadeiro campo de forças em que alternam segredo, dúvida e desvendamento, o conto tem por fio condutor a descoberta da verdade tornada urgente para Faustina, minada pela angústia e mergulhada num permanente confronto entre o conservadorismo herdado da tradição e um presente caracterizado pelo "ambiente de desmoralização geral" (idem: 50) e de "abandalhamento dos costumes" (idem: 49) em que procura o seu lugar. De salientar ainda o estado emocional dessa mãe apegada aos valores tradicionais, ${ }^{2}$ apresentada de "expressão crispada" (idem: 47) e a evitar o olhar dos outros, constantemente assaltada por "palpitações do coração", "tremuras nervosas" (idem: 43) ou "suores súbitos" (idem: 49) e sofrendo "de desprezo e pena de si própria" (idem: 43), ciente de que as suas suspeitas viriam mais cedo ou mais tarde a ser confirmadas e de que o seu desgosto, uma vez objectivado, nada mais seria do que "uma doença crónica mas não mortal que o paciente vai incorporando na sua experiência até um dia já não se lembrar de alguma vez ter vivido sem ela." (idem: 53).

Ao longo da estrutura narrativa, o leitor defronta-se com a omnipresença de termos que remetem para o campo da simulação e do segredo, ora associados ao "ser" e "fazer" (Hamon 1977: 134) desta progenitora preocupada com padrões de normalidade e com a censura alheia, ora relacionados com a postura altamente confidencial do detective e com os dispositivos de que se socorre para exercer a sua actividade, ou ainda com as inclinações de Fábio que deixam Faustina num estado de extrema aflição. Termos como "sombra", 
"camuflado", "simulando", “incógnita", "silêncio sepulcral", "esconder", "secreta”, entre muitos outros, pontuam a narrativa, orientando os passos destas personagens moldadas por uma cultura de matriz patriarcal e predominantemente machista, em que a homofobia e o complexo da honra e vergonha se manifestam de forma premente, como bem o salientou o antropólogo Miguel Vale de Almeida (2000).

Mentiras, segredos, silêncios, simulacros e não-ditos vêm constantemente à tona neste ambiente de conspiração silenciosa onde o tabu social, a discriminação e as represálias afectam experiências de vida reduzidas à clandestinidade, obrigando corpos e sexualidades dissidentes a permanecer enclausuradas no armário (Sedgwick 2008). A natureza sigilosa e a discreta vigilância do detective, que não hesita em aconselhar Faustina a instalar um aparelho de escuta telefónica para espiar as conversas do filho, ilustram claramente o controlo social exercido sobre os indivíduos, a "mecânica do poder" que disciplina os corpos, nos termos apresentados por Foucault (1975).

Atentemos no incipit centrado na determinação de Faustina em enfrentar o Mal, metaforizado na caixa de Pandora que ameaça a sua "paz doméstica", para retomarmos o título de um romance da mesma autora (Veiga 1999):

Três vezes estendeu a mão para o auscultador do telefone e três vezes emendou o gesto, concedendose um tempo que já não era de reflexão mas de expiação antecipada, consciente como estava da caixa de Pandora que por sua livre vontade se preparava para abrir. (Veiga 2003: 43)

Quando, três dias depois, Lamartine a convoca para uma nova reunião a fim de lhe expor os resultados da investigação, vê-se assaltada por inúmeras interrogações que se conjugam com uma ansiedade crescente:

Faustina, em pânico, inventou compromissos para adiar a leitura da sentença por mais três dias, findos os quais já se conseguia vislumbrar a orientar-se no seu mundo de trevas como uma toupeira confinada ao seu território, a mãe coragem de um filho homossexual. (idem: 55)

Destaque-se, nesta passagem em que se encontra a única ocorrência do vocábulo "homossexual" e em que os termos "trevas" e "toupeira" se enchem de significado, ${ }^{3}$ a 
presença do número três, ${ }^{4}$ cuja carga simbólica remete para a união e o equilíbrio procurados por esta mãe: união e reencontro com o filho com quem mantém relações distantes dominadas pelo silêncio e incomunicabilidade mas também reencontro consigo mesma, após "pedidos mudos de socorro" (idem: 43), que este número também simboliza. Representando a harmonia e o equilíbrio dos contrários e rompendo ainda com dualidades e antagonismos, o número três inscreve-se aqui como terceira via possível ou "zona de potencialidades" (Edelman 1994: 114) em que se cabem as identidades queer: um terceiro campo a desafiar binarismos e determinismos que estruturam e condicionam as relações interindividuais, como procuraremos ver a seguir.

Sem rodeios, Lamartine dá finalmente a conhecer o resultado das suas investigações:

O seu filho não anda com nenhum homem nem nenhuma mulher em particular. 0 colega que lhe telefona para casa é de boa família e não se apurou que tenham encontros íntimos. Gostaria de ficar por aqui, mas... a verdade é que se passa alguma coisa. 0 seu filho, minha senhora, dança num clube nocturno. (Veiga 2003: 56)

Perante a incredulidade de Faustina e para que se rendesse à evidência, o detective mostra-lhe uma fotografia tirada com uma câmara oculta em que o filho aparece vestido de bailarino e de mascarilha no rosto, a dançar num clube para cavalheiros. Apiedado da ingenuidade desta mãe, ajuda-a a empreender, por meio de um hábil interrogatório, uma busca de elementos e pistas susceptíveis de indiciar a inclinação do filho: a destreza e flexibilidade evidenciadas nas aulas de ginástica, a íntima relação com Luciano, um amigo muito próximo cuja morte repentina o deixou inconsolável, as amizades, visitas e saídas exclusivamente masculinas que "se multiplicavam ameaçando o baluarte da casa como térmitas vorazes ao assalto das fundações" (idem: 66), conjugando-se numa "lenta maturação para a catástrofe" (idem: 67) agora revelada.

Se Faustina, "pouco versada em ballet moderno" (idem: 57) se recusa, num primeiro tempo, a imaginar Fábio a fazer piruetas e a gesticular como as bailarinas, reconforta-se com a "esperança de que a dança do filho fosse mais orientada para o conturcionismo ou, no caso do ballet clássico, para as danças cossacas" (ibidem), bem mais viris e condizentes com 
a masculinidade hegemónica (Connell 2005) instituída pelo heteropatriarcado. ${ }^{5}$ Ser bailarino era, afinal:

[...] diferente e menos comprometedor do que se se tratasse de um procedimento homossexual puro e simples mas a exibição do filho num tablado, em maillot cor de carne, e a estratégia de manter oculto este lado da sua vida, faziam suspeitar de uma sensibilidade feminina em colisão com o seu verdadeiro sexo. Tudo questões gravíssimas e nada fáceis de debater, tanto mais que era uma mulher só. (Veiga 2003: 58)

O desamparo desta mãe é aqui reforçado pelo facto de lhe faltar o pilar masculino, destacando-se a ideia de fragilidade e dependência da mulher, reduzida a um estatuto inferior numa relação especular desvalorizante espelhada na "valência diferencial dos sexos" simbólica e socialmente construída, em que o masculino e o feminino se relacionam de forma hierárquica, assimétrica e desigual, como claramente o demonstrou a antropóloga francesa Françoise Héritier (1996: 22; 2005: 46). Com a esperança de ainda poder "normalizar" o filho, Faustina não hesita em solicitar a ajuda de Mariana, uma jovem manequim despida de quaisquer preconceitos e totalmente disponível para o amor, a fim de medir a (in)sensibilidade do filho à sedução feminina e testá-lo em termos de sexualidade predatória, como se pode esperar num jovem da sua idade.

Enquanto aguardam o regresso de Fábio e num ambiente propício a íntimas confidências, Faustina e Mariana discorrem sobre o passado de cada uma, deixando entrever uma série de dramas que as fustigaram desde a primeira infância, entre acidentes violentos, separações dolorosas ou mortes cruéis. O leitor é então surpreendido com as revelações de Faustina sobre a sua infância e adolescência, revelações em que o gender trouble (Butler 1990) ganha nítidas configurações:

Eu era tímida, insegura, receava os animais, e, embora gostasse muito da vida ao ar livre, qualquer participação nos trabalhos da quinta deixava-me prostrada. Já a minha irmã, mais nova do que eu três anos, à parte a questão do sexo errado tinha todas as condições para lhes agradar pois salientava-se pela robustez, o desembaraço e todas as predisposições inatas que se costuma atribuir aos rapazes.

Muito criança ainda recusou-se a usar vestidos e não me lembro de a minha mãe ter feito nada para se 
opor aos seus caprichos, pelo contrário, deixou-a seguir as suas inclinações à vontade, mesmo que isso significasse expor-se a perigos e cansaços incompatíveis com a sua idade e a sua condição feminina. (Veiga 2003: 73-74)

Abalando o quadro normativo das categorizações, a mesma ambiguidade ou fluidez se verifica na descrição do irmão cuja constituição simultaneamente delicada e resistente uma combinação de força e fragilidade servidas "na embalagem enganadora de uma cara de anjo" (idem: 74) - contrasta com a da irmã que "aos doze anos pelos modos e a linguagem não se diferencia[va] de um moço de estribaria" (idem: 75). Através da descrição destas crianças em fase de aprendizagem de comportamentos e de categorias classificatórias, questionam-se paradigmas essencialistas, dualismos e clivagens de uma cultura construída segundo a lógica da "dominação masculina" (Bourdieu 1958). Nestas "descoincidências" (Jagose 1996: 3) entre sexo biológico e género, definem-se os contornos de um entrelugares, uma zona movente e de indeterminação onde o diverso se erige como contraponto dos lugares fixos da cultura.

A mesma saída do tradicional padrão binário ocorre quando, na companhia de Mariana, Faustina decide seguir o filho até ao clube de cavalheiros onde entram disfarçadas de homens e assistem à performance dos bailarinos, de mascarilhas e rostos maquilhados, vestidos com saias de um vermelho exuberante e exibindo posturas e movimentos sensuais e extravagantes ao som das danças de Brahms, num alternar de momentos "de explosão apoteótica e de calma voluptosidade" (Veiga 2003: 83) que seduzem Faustina, rendida à irrupção da beleza deste espectáculo em que masculino e feminino se confundem e em que o estranho, o invulgar, o indizível se materializam num processo catártico e libertador: “[...] era a primeira vez que a dança lhe aparecia como uma catarse realmente violenta, a materialização do indizível, do que só em sonho o homem ousa revelar a si próprio." (ibidem).

Pela componente teatral e o elevado grau de estilização e artifício, estas danças de Brahms assumem contornos camp (Sontag 1964: 1-13), destacando-se nelas a tendência para o exagero, a extravagância, o gosto pelo exuberância despertado pelos movimentos dos corpos finos e esguios dos bailarinos, que "se articulavam na perfeição com a sedução das saias vermelhas" (Veiga 2003: 82), corpos sedutores e saturados de sensualidade, 
prazer e duplicidade. “Camp é o triunfo do estilo epiceno. (A conversibilidade de 'homem' e 'mulher', de 'pessoa' e 'coisa')", refere, a este propósito, Sontag (1964: 4).

Dotados de um "corpo estranho" (Louro 2004) e invulgar, um corpo liberto das limitações e divisões biológicas e guiado por desejos próprios, Fábio e os restantes bailarinos personalizam o queer, numa fluidez simultaneamente desestabilizadora e fascinante em que se afirmam identidades alternativas, nómadas, atraídas pelo "múltiplo", pelo "não-Uno", no sentido proposto pela filósofa Rosi Braidotti, na perspectiva de uma nova leitura da realidade: "No contexto atual, temos que repensar as relações com a alteridade num sentido nómada. A alteridade nómada não é uma, mas múltipla", lembra Braidotti (2003: 29). Estas subjetividades nómadas e rizomáticas (Deleuze/Guattari 1976) ${ }^{6}$ envolvem-se num movimento de desterritorialização e de explosão de fronteiras, contrariando as estruturas do "biopoder" (Foucault 1976) e incitando-nos a pensar as relações entre os indivíduos num regime de ampla proliferação de dissemelhanças e de rejeição do straight (Wittig 2001), da cultura da conformidade. Superando o confinamento a determinadas posturas ou etiquetas, a identidade queer é, por essência, variável, instável, mutável, dinâmica e sobretudo plural.

Fábio que, "por natureza ou por artifício calculado" (Veiga 2003: 62) - reforçando a ideia de que o género e a identidade se constroem através da repetição de performatividades socialmente construídas, como bem o evidenciou Judith Butler (1990) "era sereno, reservado e discreto e usava o mutismo como outros usam a eloquência, para transmitir ao mundo o melhor de si próprio" (Veiga 2003: 62), contraria, com estas características geralmente atribuídas ao feminino, os cultos e códigos da masculinidade hegemónica e as marcas de virilidade que definem, segundo Bourdieu, os "verdadeiros homens" (Bourdieu 1958: 58). De notar ainda a importância dos trajes usados como marca de resistência às dicotomias de género, como tentativa de contrariar um sistema que teima em reproduzir binarismos opressores que confinam os indivíduos e inibem manifestações de desejo.

Aconselhadas pelo porteiro que as expulsou depois de descobrir que eram mulheres disfarçadas de homens, Faustina e Mariana vão parar à Casa da Rosa, um salão de chá de 
alto requinte e absolutamente inesperado naquela aldeia remota. Passado algum tempo no local, apercebem-se de que estão rodeadas de mulheres muito atraentes e vestidas a preceito, entre as quais Rosa, a irmã que Faustina perdera de vista, uma "esbelta amazona de andar ligeiro", proprietária do clube feminino sobre a qual se interrogam, equacionando perspectivas que tendem a desconstruir paradigmas monolíticos e essencialistas:

- É uma mulher? Ou um homem? - indagou num tom de voz zombeteiro. - Eu diria que é um homem.

- 0 hábito não faz o monge - também tu estás vestida à homem e tens nome de mulher. (Veiga 2003: 93)

Atentemos ainda na descrição dos espaços em que a acção decorre, remetendo para as duas vertentes - regulatória e emancipatória - em torno das quais o conto se constrói, incitando-nos a interrogar o queer a partir da relação entre centro e margens. 0 ambiente pequeno-burguês do prédio citadino em que se situa o escritório de Lamartine, composto por um conjunto de casas bem ordenadas, decoradas com "paninhos de renda e outros lavores femininos a inspirar confiança, asseio, respeitabilidade" (idem: 55) e onde se reproduzem “cenas pacíficas de honestas vidas de família” (idem: 45) - modelo conservador e reprodutivo do heteropatriarcado - contrasta com o clube masculino ou o salão de chá, ambos situados em locais afastados da cidade e de difícil acesso, a que se chega por uma estrada secundária até ao cimo da serra, repleta de desvios que se embrenham numa mata de eucaliptos e conduzem a uma pequena povoação a emergir no negrume da noite. Nesse ermo perdido, o clube esconde-se numa casa isolada com portas e janelas fechadas, no interior da qual "um pequeno labirinto de escadas e corredores desembocavam na cave" (idem: 81), um antro secreto onde a "Serpente do Mal" (idem: 65) actua para lá da heteronorma e de categorizações estritas. Bailarinos-performers e espectadores movidos por uma pulsão voyeurística diluem-se na vertigem desse bas-fond onde as possibilidades de libertação se multiplicam e onde a carga erótica se vai-se adensando, num misto de sedução, prazeres e êxtases. Verdadeiro refúgio de homossociablidade e homoerotismo, este antro isolado constitui um espaço "heterotópico" ou "contra-espaço" propício a estratégias de resistência à homogeneidade e à contrução de outro tipo de relações, como indica Foucault: 
[...] des lieux réels, des lieux effectifs, des lieux qui sont dessinés dans l'institution même de la société, et qui sont des sortes de contre-emplacements, sortes d'utopies effectivement réalisées dans lesquelles les emplacements réels, tous les autres emplacements réels que l'on peut trouver à l'intérieur de la culture sont à la fois représentés, contestés et inversés, des sortes de lieux qui sont hors de tous les lieux, bien que pourtant ils soient effectivement localisables. (Foucault 2009 : 39)

Nesse lugar absolutamente "outro", marcado pela ruptura e pela diferença, convergem corpos desejantes e desejados capazes de "levar a cabo operações de contraprodução de prazer" (Preciado 2014: 13), com performances artísticas e queer que subvertem a ordem, a repressão, o controlo infringido pelo poder normativo. 0 mesmo acontece como a Casa da Rosa, o clube de mulheres perdido no mesmo lugarejo, que surpreende pela sua modernidade, sobriedade e requinte, repleto de sons e perfumes voluptuosos, onde corpos de ladys e butchs se abandonam à mais profunda lascívia, desafiando os estereótipos da feminilidade. Estes corpos eróticos subvertem padrões impostos, transgridem normas e papéis preestabelecidos que tolhem a individualidade e a autenticidade, como observa Georges Balandier:

La transgression se manifeste à plein dans les sociétés de la tradition à norme, codages et impositions rigoureusement définis, à large sacralisation; elle recule ou se nie, en se banalisant ou en se transformant en agression totale, dans les sociétés de la modernité actuelle, éclatées, mouvantes et "permissives" par le fait du brouillage de tous les repères. (Balandier 1985: 44)

Saliente-se aqui - lembrando também a importância das artes e da literatura em toda a produção de Teresa Veiga - o facto de Faustina estar precisamente a ler a correspondência de Katherine Mansfield (1988-1923), autora algo avessa à ordem burguesa e cuja obra se reveste por vezes de tonalidades homoeróticas, tal como na seguinte passagem do conto At the Bay, em que a jovem Beryl se desnuda sob o olhar libidinoso de Mrs. Kember:

And Beryl stepped out of her skirt and shed her jersey, and stood up in her short white petticoat, and her camisole with ribbon bows on the shoulders.

"Mercy on us", said Mrs. Harry Kember, "what a little beauty you are!” 
"Don't!" said Beryl softly; but, drawing off one stocking and then the other, she felt a little beauty. (Mansfield 1988: 54)

“L'œuvre de Katherine Mansfield [...], sous couvert de l'implicite, du symbolique et du métaphorique, aborde la rencontre sexuelle jusque dans les tabous tels que le lesbianisme", refere, a este propósito, Delphine Soulhat (2011: 11). Também não será por acaso que o sorriso dos bailarinos do clube de cavalheiros é comparado ao da enigmática Gioconda, sorriso este "transplantado com êxito sobre uma tela humana" (Veiga 2003: 82) em que o masculino e o feminino se confundem. Não podemos deixar de estabelecer aqui um paralelo com o ready made do pintor dadaísta Marcel Duchamp, datado de 1919, que reproduz uma Gioconda marcadamente queer, de bigode e barba, e com o título particularmente provocador $L H O O Q,{ }^{7}$ fazendo explodir as fronteiras entre masculino e feminino. Mencione-se ainda que o próprio Marcel Duchamp não hesitou em adoptar o pseudónimo feminino de Rrose Sélavy (ou “Éros, c'est la vie”), tendo sido várias vezes fotografado por Man Ray em poses que confundem as noções de sexo, género e identidade.

Contudo, estas metamorfoses singulares e/ou coletivas, de tonalidades queer, só ganham, no conto que aqui nos ocupa, uma aparente aceitação no plano do devaneio onírico. Com efeito, o leitor descobre, no fim da narrativa, que foi num sonho em que mergulhou ao coser o casaco do filho, que esta mãe, presa às limitações que a impedem de despir o colete de forças do conformismo, se abriu a estes devires multidirecionais que ultrapassam os constructos heteronormativos socialmente impostos.

Neste conto, Teresa Veiga explora assim a violência hegemónica, mostrando-nos os vários rostos da opressão - dominação, discriminação e estigmatização - nas relações de poder instituídas pelo heteropatriarcado, negando a alguns o direito de assumirem livremente a sua própria natureza e condenando a um insidioso ostracismo os que não entram nos moldes estritos de género e sexualidade, como ilustrado na seguinte passagem:

- Pior do que não ter tido pais - disse ela - é sentirmo-nos rejeitados por aqueles que nos deram a vida, sem a consciência nos acusar de outro crime senão de sermos como somos e não como queriam que fôssemos. (Veiga 2003: 73) 
O facto do abraço entre Faustina e a irmã lésbica apenas se concretizar em sonho mostra-nos o longo caminho que resta a percorrer na construção de uma ética que rompe com modelos rígidos e paradigmas cristalizados, inscrevendo o indivíduo numa dinâmica variável, fluída, nómada e profundamente tolerante.

\section{NOTAS}

${ }^{1}$ História da Bela Fria (contos), Lisboa, Cotovia, 1992: Prémio de Ficção do Pen Clube Português e Grande Prémio de Conto Camilo Castelo Branco 1992; Uma aventura secreta do Marquês de Bradomín (contos), Lisboa, Cotovia, 2008: Grande Prémio de Conto Camilo Castelo Branco 2008; Gente melancolicamente louca, Lisboa, Tinta da China, 2015: Grande Prémio de Conto Camilo Castelo Branco 2016.

2 "Faustina só caía em profunda reflexão quando entrava numa casa habitada por gente velha que se sentava há cinquenta anos nas mesmas cadeiras de costas [...]. Pensar que esse mundo extinto ainda existia algures nalguns redutos sagrados e privar com eles mesmo por pouco tempo acalmava-a e revigorava-a" (Veiga 2003: 54).

${ }^{3}$ Remetendo para a ideia de vergonha interiorizada numa sociedade tradicionalmente hipócrita assim como para as práticas repressoras que confinam e oprimem os seres.

4 Presença esta reiterada ao longo do conto: "três vezes", "três vezes", "três andares", "três dias depois" "por mais três dias", "fome de três dias" (Veiga 2003: 59) "três meses antes" (idem: 66).

5 Particularmente desenvolvido pelos estudos de género e teoria queer a partir dos conceitos de "patriarcado" e "heterossexualidade", constitui-se como uma organização sociopolítica baseada na dominação masculina e na heterossexualidade como norma hegemónica. 
6 Segundo os autores, o rizoma remete para a ideia de "conexão", "heterogeneidade" e "multiplicidade", princípios reunidos no conceito de "identidade-rizoma"' que constitui a base da poética da Relação definida por Édouard Glissant (La poétique de la Relation, Paris, Gallimard, 1990).

${ }^{7}$ Que pode simultaneamente ser lido como homófono do inglês look, ou uma halografia de "elle a chaud au cul" ("ela tem o rabo quente").

\section{Bibliografia}

Almeida, Miguel Vale de (2000), Senhores de si. Uma interpretação antropologica da masculinidade, Lisboa, Fim de Século [1995].

Balandier, Georges (1985), Le détour. Pouvoir et modernité, Paris, Fayard.

Bourdieu, Pierre (1998), La domination masculine, Paris, Seuil.

Butler, Judith (1990), Gender Trouble: Feminism and the Subversion of Identity, London-New York, Routledge.

Connell, Raewyn (2005), Masculinities, Berkeley, University of California Press.

Deleuze, Gilles / Félix Guattari (1976), Rhizome, Paris, Éd. de Minuit.

Edelman, Lee (1994), Homographesis: Essays in Gay Literary and Cultural Theory, New YorkLondon, Routledge. 
Foucault, Michel (1975), Surveiller et punir, Paris, Gallimard.

-- (2009), Le corps utopique. Les hétérotopies, Paris, Lignes.

Hamon, Philippe (1977), "Pour un statut sémiologique du personnage", in Poétique du récit, Paris, Seuil, 115-180.

Héritier, Françoise (1996), Masculin/Féminin. La pensée de la différence, vol. 1, Paris, Éditions Odile Jacob.

-- (2005), Hommes, femmes. La construction de la différence, Paris, Éditions Le Pommier.

Jagose, Annamarie (1996), Queer Theory: an introduction, New York, New York University Press.

Louro, Guacira Lopes (2004), Um Corpo Estranho. Ensaios sobre sexualidade e teoria queer, Belo Horizonte, Autêntica Editora.

Mansfield, Katherine (1988), At the bay and other short stories. Sur la baie et autres nouvelles, trad. Magali Merle, Paris, Librairie générale française.

Preciado, Beatriz (2014), Manifesto contrassexual, trad. Maria Paula Gurgel Ribeiro, São Paulo, n-1 edições.

Sedgwick, Eve Kosofsky (2008), Epistemology of the closet, Berkeley-Los Angeles-London, University of California Press.

Sontag, Susan (1964), "Notas sobre o camp", <https://perspectivasqueeremdebate.files. wordpress.com/2014/06/susan-sontag_notas-sobre-camp.pdf> (último acesso em 04/12/2018). Soulhat, Delphine (2011), "Poétique de la rencontre dans les nouvelles de Katherine Mansfield", Thèse de Doctorat, Université Paris Ouest Nanterre La Défense, <https://bdr.parisnanterre.fr/theses/internet/2011PA100129_diff.pdf> (último acesso em 04/12/2018).

Veiga, Teresa (1999), A paz doméstica, Lisboa, Cotovia.

-- (2003), As enganadas, Lisboa, Cotovia.

Wittig, Monique (2001), La pensée straight, Paris, Éditions Balland. 
Maria Araújo da Silva é Professora Associada na Universidade da Sorbonne (Sorbonne Université) desde 2006. Autora de uma tese de Doutoramento sobre Maria Ondina Braga (2005), trabalha sobre literatura portuguesa contemporânea e interessa-se particularmente por questões de género, corpo e sexualidade. Obteve, em 2009, o Prémio Literário Maria Ondina Braga e publicou vários artigos sobre literatura portuguesa contemporânea em obras colectivas e revistas de estudos lusófonos. Membro do CRIMIC - Sorbonne Université, codirigiu os volumes Femmes oubliées dans les arts et les lettres au Portugal-XIXe-XXe siècles (2016), Exiliance au féminin dans le monde lusophone, XXe-XXIe siècles (2017) e Paris, Mário de Sá-Carneiro et les autres (2017). 